\title{
The Tibetan Institutionalisation of Disputation: Understanding a Medieval Monastic Practice
}

\author{
Jonathan Samuels*
}

Within Europe, there developed what has been described as a »medieval culture of disputation «. ${ }^{1}$ This description seems equally apt with regard to certain societies in Asia that had strong Buddhist scholarly traditions. A formalised practice of disputation is one of the many correspondences that exists, for instance, between the scholarly cultures of medieval Europe and Tibet. In Europe, various intellectual and social movements contributed to the eventual decline of scholasticism, the system to which disputation was central. But in Tibet, disputation still holds pride of place in a style of learning that is essentially medieval in origin. The existence of this "living tradition" and the availability of plentiful sources hailing from the medieval scholastic tradition may well be seen as major assets when it comes to understanding the earlier Tibetan practice. But confusion about sources, domains, and claims of continuity appear to have discouraged efforts in this direction. The current article is the first to consider Tibetan monastic disputation in historical terms. Through the clarification of boundaries, the identification of relevant historical sources, and by means of comparison with contemporary practice, it takes the first steps to understanding the evolution of disputation, specifically within institutional contexts.

Keywords: scholasticism; disputation; Tibet; Buddhism; monasteries; institutionalisation

\section{Buddhist Scholasticism: Representation Through Abstraction}

The term "scholarly« has long been used to describe some Buddhist traditions, including, in the case of Tibet, certain of those that first emerged during its imperial period (seventh-ninth centuries CE) and which drew heavily on forms of thinking and practices developed in Indian Buddhist monastic centres. Viewing such Buddhist traditions in terms of "scholasticism« is, conversely, an idea of far more recent provenance, advocated by Cabezón. ${ }^{2}$ Taking inspiration from Makdisi, who, in referring to the "scholastic method in the Muslim East«, had

\footnotetext{
* Correspondence details: Jonathan Samuels, Faculty of Oriental Studies, Oriental Institute, University of Oxford, Pusey Lane, Oxford, OX1 2LE, UK; email: jonathan.samuels@orinst.ox.ac.uk.

1 Novikoff, Medieval Culture of Disputation.

2 Cabezón, Buddhism and Language and id., Scholasticism.
} 
proposed that the central feature of scholasticism might be conceived of within the unfamiliar setting of medieval Islam, ${ }^{3}$ Cabezón argued that scholasticism represented an analytical category, potentially useful in the comparison of various religious and philosophical traditions. Buddhist scholastic traditions are not linked to those of the medieval Christian and Muslim worlds through genealogy, literary heritage, or historically attested channels of discourse and exchange. Thus, the dialogue in which scholarly aspects of the traditions are compared is structured around perceived correspondences and affinities. Cabezón's notion of scholasticism might seem ideally suited for this dialogue in that it encourages understanding of the phenomenon in terms of polythetic convergences. The motives behind such attempts to spread scholasticism's net are unimpugnable, and the engagement may prove mutually beneficial. At the same time, there is an internal dynamic to the dialogue. Within the framework of comparative discourse, perhaps inevitably, those representing these "new « branches of scholasticism feel it incumbent on themselves to approach the matter as though they are mounting a case for their inclusion, a feeling that is hardly likely to be reciprocated by those in traditional medieval studies, for whom scholasticism is probably seen as native territory. This imbalance is something that should perhaps neither be disregarded nor seen as wholly objectionable. For the newcomers, a more self-conscious, questioning dimension to representation would hopefully challenge the uncritical assumption that the framework of scholasticism has some form of universal validity, and waits anxiously to embrace them.

According to the polythetic approach, scholasticism, and scholarly traditions more generally, are understood through abstraction. Again, this seems ideal, not to say necessary for comparative discourse, as the abstract intellectual domains of logic, hermeneutics, and philosophy appear to be the most obvious meeting grounds for those investigating Buddhist, Christian, and Muslim scholarly traditions. For many in Buddhist and Tibetan studies this territory is extremely comfortable, but equally, I would argue, potentially perilous. Those who specialise in scholastic Buddhism generally understand their task to be one of identifying the essential views, axiomatic principles, and rules of logic that they see as defining their domain, then exploring how these have been interpreted by various individuals and schools. Any "historical « dimension to this is, similarly, largely confined to the realm of ideas: their origin, development, and influence. For many, therefore, the intellectual represents the entirety of the scholarly realm. Interactions within this realm are seen as limited to those between the writers and texts judged to be interlocutors within a religio-philosophical discourse. This circumscription seems to justify viewing the scholastic realm as one virtually sealed-off from the social, political, and other spheres, and studies that indicate awareness of the intellectual realm being engaged in dialectical discourse with such spheres are rare. Hence, in contrast to the treatment of European scholasticism in mainstream medieval studies, there is little perceived need to explain or demonstrate what relevance texts and their contents had to individual settings: how they might have informed action in institutional contexts, helped shape and create institutions and their practices, or impacted upon wider societies. 
Considering for a moment how these factors play into representation, portrayals of the Buddhist scholastic tradition often take the form of expansive overviews, which endeavour to encapsulate, with selected scriptural and treatise citations, the continuous "spirit" of scholastic enquiry that is supposed to have infused and sustained Buddhist traditions for roughly two and a half millennia; a spirit that, having originated with the Buddha himself, is meant to have flowered to its fullest in the great medieval Indian monastic centres, before spreading to Tibet and elsewhere. These ambitious efforts should not be mistaken for historical synopses. It would be misleading to suggest that those in Buddhist or Tibetan studies are in a position to provide millennia-hopping distillations of scholastic traditions in history. Quite aside from the question of sources, such overviews are not the products of critical and rigorous processes of academic investigation and discourse, something illustrated by the fact that they give us little indication of how the "spirit « was instantiated, other than to refer back to the internal, scholarly dialogue.

The foundation for the "history" of scholastic traditions in Tibet is the notion that they, together with other elements of religious culture, were derived from India. Notions of continuity are constructed around what is often designated the "Indo-Tibetan tradition of Buddhism«. The great centres of Buddhist learning in India, such as Nālandā and Vikramaśila (the collective life of which spanned the fifth to the thirteenth centuries $\mathrm{CE}$ ), are seen as the original homes of scholastic Buddhism. Academic writings regularly echo the claims of tradition, according to which Tibetans have loyally preserved the Indian Buddhist scholarly practices that originated in the great centres. The popularity and influence in Tibet of writings by certain Indian thinkers is presented as primary evidence of Indo-Tibetan continuity. Most important in the scholastic domain are the works of Dignāga (c. 480-540 CE) and Dharmakirti (c. 600-660 CE), who were responsible for developing the Buddhist logico-epistemological system (Sanskrit: pramāna). Various aspects of the "Indo-Tibetan « framework might be criticised, but on the level of individual exchanges, Tibetan connections with these centres are a matter of historical record. Assertions of continuity are also verifiable in relation to the aforesaid scholastic writings. In Tibet, these works have been the subject of enduring interest, manifesting in translation (and retranslation), text production, and centuries of learning and commentarial composition. The case regarding historical practices, such as those of disputation, must be seen as entirely different. What Tibetan sources tell us about disputation practices will be considered below, but in terms of how such practices might relate to Indian ones, it should be remarked that despite centuries of scholastic activity at Indian monastic centres such as Nālandā, primary sources offer few clues regarding the way that disputation was performed in them. Even the accounts by Chinese and Tibetan visitors, which are regarded as among the clearest contemporary reports, and which contain references to formalised disputation, provide precious few details. More generally, perhaps the most extensive and oft-cited sources on the scholastic organisation at centres like Nālandā are certain Tibetan ones, but these were composed centuries after these centres' final abandonment, rendering reports of continuity suspiciously self-referential. Hence, while it can be stated with certainty that disputation had a major place in both Indian and Tibetan medieval monasteries, the paucity of Indian sources makes it impossible to verify claims of detailed correspondences. 
Claims of continuity (and to some extent the whole conception of the practice itself) often seem to rest on an unquestioned premise, namely, that disputation is something that can be understood as a single, coherent, continuum of tradition, not reflecting, but abstracted from a vast array of individual historical, socio-cultural, and institutional settings in which it may have operated - surely an unrealistic way to approach the history of any organised human activity. The processes of extraction that prove so useful when dealing with logical and philosophical principles expressed in the scholarly texts can hardly be applied to this sphere. Even the claims of continuity themselves have to be understood in terms of their functions within individual socio-cultural settings. Assertions of maintaining the scholastic traditions of Nālandā, such as occur in relation to Tibetan or Sri Lankan monasteries, have clearly been employed as legitimisation devices for monastic authority, used to construct institutional history or patch over troubling ruptures in it, and have even fed narratives of ethno-religious exceptionalism.

\section{Conceiving Scholasticism in a Tibetan Historical Landscape}

In the remainder of this article, the view taken is that the topic of disputation is one that needs to be investigated and understood within specific historical settings. In terms of the Tibetan medieval practice, it is concerned with three crucial issues: 1 . The relationship between scholarly literature and practice; 2 . The form of medieval disputation; 3 . The practice's purposes and aims. The basic argument is that attempts to address such issues and indeed gain a realistic understanding of the practice can make little progress unless there is greater preparedness to conceive of it in terms of specific historical institutions, rather than just intellectual content or religious goals.

If practices such as disputation need to be approached and understood in terms of individual historical and institutional settings, the same might also seem to apply to scholasticism itself. Treating it either as a given (as a convenient way to refer to Buddhist scholarly tradition) or in an abstract fashion seem unsatisfactory, particularly as, in the latter case, it would appear to give licence to removing it from the aforesaid settings. Furthermore, while the thoughts and writings we are dealing with indisputably share generic similarities with those in other scholarly traditions, what guarantee is there that they are anything more than a loosely-connected set of elements, with nothing of the organisation and order that characterises those that could be said to belong to a single school of thought, method, or approach, as in the case of European medieval scholasticism? Tibetan history has not generally been defined by intellectual, social, or political movements. Despite this, when used in reference to scholarly traditions associated with the monastery of Sangpu (gSang phu), ${ }^{4}$ the notion of scholasticism seems entirely appropriate. In recent years, this monastery's reputation has been somewhat rehabilitated, with some studies recognising its vital role in the evolution of Tibetan scholastic traditions. ${ }^{5}$ In such studies, the approach that originated there, beginning in the eleventh century, is sometimes referred to as "scholasticism «. ${ }^{6}$ I believe, however,

4 The Tibetan terms and names here are firstly rendered in simplified phonetics, providing an approximate guide to pronunciation. The version in brackets follows the Wylie transliteration system and is based on Tibetan orthography.

5 Such as Hugon, Enclaves of learning.

6 The monastery (full Tibetan name, gSang phu ne'u thog) was founded in 1072/1073. 
that the case for identifying "Tibetan scholasticism« with Sangpu traditions begs further development, especially as the language and framework that can be used for representing these traditions is entirely indigenous in origin, helping allay any concerns that discussions about scholasticism here require the superimposition of some "alien" concept onto the Tibetan setting. More generally, rooting discussion in the Sangpu traditions means that we avoid dealing with scholasticism in an ahistorical, abstract fashion (and circumvent various self-created debates about what qualifies as Tibetan scholasticism). The centralising concept, embodying the approach pioneered at Sangpu is that of tsenyi (mtshan nyid). Two new glosses for the term seem to have emerged from Sangpu. It appears, perhaps originally, to have been associated with the pramanna logico-epistemological tradition (Tibetan: tshad ma) championed there, and perhaps even specifically with the pivotal treatise composed by the Indian master Dignāga, Compendium of Valid Means of Knowledge (Sanskrit: Pramānasamuccaya; Tibetan: Tshad ma kun btus). But the two most significant figures in the creation of Sangpu's scholastic traditions - the monastery's second and sixth abbots, Ngog Lotsawa (rNgogs blo ldan shes rab, 1059-1109) and Chapa Chökyi Senge (Phywa pa Chos kyi seng ge, 1109-1169) - were also instrumental in the development of an indigenous theory of definitions, in which the term tsenyi was chosen to denote the definitions in question. The quest for establishing the characteristics defining a particular thing and arguments about what constituted the correct version of that definition seem to have long been regarded as cardinal to the approach followed at Sangpu. The two glosses converged, and the term tsenyi came to encapsulate the whole Sangpu system. The creation of this essentially new concept was itself a sign of the indigenous tradition's growing confidence. Prior to this, notions related to logic and reasoning had been conveyed through standardised terms, dutifully translated from Sanskrit. ${ }^{7}$ But the tsenyi-concept expressed something new and followed no Sanskrit precursor. It was also at Sangpu that the concept of what is commonly referred to as the Tibetan "scholastic curriculum " was first created. As in the treatises composed by Sangpu scholars, the approach to learning seems to have been heavily dialectical in character. Tradition credits Chapa Chökyi Senge with creation of the structure and rules for formal disputation. The Sangpu approach proved influential: numerous satellites, commonly referred to as tsenyi-»sections" or "schools" (mtshan nyid kyi grwa) were founded, often as separate divisions within pre-existing monasteries. ${ }^{8}$

A point not previously remarked on is the role of the tsenyi-concept in the construction of personal and group identity. Distinguishing themselves from the various village-based ritualists, contemplatives, and monks of varying description (especially those devoted to tantrism), individuals who engaged in this dialectically orientated approach began to refer to themselves and their community, who were almost exclusively monastic, as "tsenyi-ists" (mtshan nyid pa). For centuries, what might be termed the "tsenyi-movement « flourished contemporaneously with medieval European scholasticism. The form of critical thinking that it promoted, the dialectical nature of its literature, the various methods and techniques employed by it (including public disputation), and its gradual move towards standardised education and formal examination, leading to the awarding of titles, present us with a cluster of features corresponding with those found in the scholasticism of medieval Europe.

7 During imperial times, the Tibetan terms rtog ge and gtan tshigs had been created. They were supposed to represent equivalents of the Sanskrit concepts of tarka and hetu.

8 The term bshad grwa was also used for these. 
Identifying scholasticism with the Sangpu tradition may raise questions about how to characterise and classify various nexuses of activity that occurred outside it. A great deal of work in medieval Tibet that had no direct connection with Sangpu, including that related to literary production, codification, and the systematisation of written corpuses, must be recognised as scholarly activity. However, if we distinguish scholasticism from commentarial traditions (of which there were multiple variations), and understand it as a system in which a distinct method of critical thinking and dialectical reasoning were developed not simply in its writings, but were also applied to learning, particularly through techniques such as formal disputation, then nothing in medieval Tibet outside the Sangpu tradition deserves the description "scholasticism«. Sakya Pandita (Sa skya Pandita 1182-1251) is sometimes depicted as having created a scholarly system that rivalled that of Sangpu. ${ }^{9}$ In fact, although he sought to expand the vision of scholarly learning, in every other respect his acceptance of the fundamentals of the tradition conceived at Sangpu, including its dialectical approach and the centrality of disputation, was total. He neither rejected the growing notion of scholasticism nor created any alternative to it.

It is traditional to refer to an earlier and later dissemination of Buddhism in Tibet: the first running concurrent with the period of empire, and the rise of Sangpu occurring shortly after commencement of the second. Rooting understandings of scholasticism in the tsenyi-model again does not imply that activities undertaken in the pre-Sangpu era were not scholarly. The earlier dissemination saw the founding of the first Tibetan monastery, Samye (bSam yas). It hosted eminent Indian Buddhist scholars, such as Śāntarakṣita (725788) and Kamalaśila (740-795), who resided in Tibet until their deaths. While there, they composed treatises, taught, promoted the views of a particular brand of Buddhist philosophy, and oversaw translation work. As reflected in their treatises, their approach was decidedly scholarly and advocated the use of logic. Traditional accounts also report that Kamalaśila emerged victor in a monumental public disputation, thus ensuring that a more intellectual approach to Buddhism was adopted in Tibet, rather than a contemplative one. But again, we must not lose sight of the issue here: even if these figures promoted a scholarly brand of Buddhism and left their mark in the literary domain, with Śantarakșita's treatise Ornament of the Middle Way (Madhyamakālaṃkära) remaining influential and inspiring numerous commentaries, this alone does not establish that they were responsible for creation of a system or that any enduring legacy of scholastic tradition survived them. Importantly, we lack reliable records about how learning was approached at Samye and whether practices such as disputation were used. Crucially, whatever institutional structures might have supported scholastic practices appear to have perished with the empire in a spectacularly synchronised fashion. According to popular accounts, Lhalung Pelgyi Dorje (Lha lung dPal gyi rdo rje), the monk whose assassination of the Tibetan ruler Udum Tsen ('U dum btsan) in 841 triggered both the imperial downfall and the collapse of institutional monasticism at the heart of the dominion, was the abbot of Samye, the centre of scholastic activity! 


\section{Reconstructing Disputation Practice in Tibet:}

The Limits of Sources and the Confusion of Domains

Given the size of the population and the proportion of it who engaged in literary activity, the extent of the Tibetan medieval scholastic corpus is impressive. There is, however, insufficient appreciation of the narrowness of the corpus's breadth and the limitations this imposes on the historian. Those researching scholastic traditions like disputation practised in medieval Europe, for instance, are not only able to call on relevant erudite treatises and commentaries, but also more personal writings (including diaries, private letters, and epistles), official works (chronicles, court records, registers, religious rulings, and legal documents), as well as debate scripts. Such breadth, and the multiplicity of voices represented in these materials offer varied perspectives and reveal institutional and private tensions. Readings of the past that emerge from them are inevitably refined and nuanced. Many of these categories of writing, if they existed at all in Tibet, have survived only in fragmentary form and provide nothing of relevance. Tibetan materials do not even seem to compare favourably with those of other Buddhist medieval scholastic systems, such as that of Japan, which appears not to have flourished to the extent of the Tibetan one. There is no shortage of erudite Tibetan writing, especially of the commentarial variety, eloquently expressing the sophistication of scholarly thinking. But the Tibetan addiction to formulaic and idealised presentation has, frustratingly, largely succeeded in excluding from the historical record details of the actual process and routine of practices. Hagiographic writings, like those erudite works, form substantive corpuses, and are potentially useful, but disputation practice usually receives only cursory mention in them.

Anyone who has witnessed the activity currently engaged in on the dedicated area known as the "debate ground " within the main monastic centres of the Geluk (dGe lugs), ${ }^{10}$ the largest school of Tibetan Buddhism, has some inkling of the degree of formalisation and stylisation attached to the activity commonly described as "debate«. The practice has, for some centuries, been the mainstay of Geluk scholasticism, and is generally understood to have medieval roots. But the question of how the contemporary practice relates to its medieval predecessor has barely been raised. This is an issue that falls within the Rumsfeldian sphere of unknown unknowns. Significant studies cover different dimensions of the contemporary practice, viewed in the context of monastic education. ${ }^{11}$ Aside from these, the studies most readily associated with "Tibetan monastic debate« deal with a genre of texts labelled Collected Topics (bsdus grwa): ${ }^{12}$ primer material, currently used in monasteries of the Geluk and other schools, to introduce students to debate fundamentals. Tibetan has no separate term for "public disputation". A single, common term ( $r$ tsod pa) covers roughly the same range of uses as "debate« does in English. The resulting ambiguity means that the spheres of activity (that of public disputation) and literature (writings containing material perhaps relevant to the speculate, somewhat briefly $(2013,137-146)$, on how current practice may differ from that in the past. 
activity, or, more generally, polemical works or those involving dialectical exchanges on religio-philosophical topics) are never satisfactorily distinguished. Since early medieval times, the writings of the scholastic tradition have favoured a predominantly dialectical format, with authors setting out their own commentarial interpretations or presenting material that is more explicitly designed for educational uses not by exegesis, but through ideal, instructive exchanges, in which a representative of "our own system « refutes positions advanced by various real or imagined opponents. Added to this, dialectical writings use much of the same formulaic language that is employed on the debate ground. Further blurring boundaries, materials currently employed for educational purposes in Tibetan monasteries of the scholastic persuasion are not only barely distinguishable, stylistically, from material of the medieval times, in most cases they are medieval compositions: genres such as the Collected Topics can be traced directly to Sangpu, ${ }^{13}$ and most major manuals used in the Geluk system were composed in the fifteenth century. Furthermore, notwithstanding the upheaval that ensued following the Chinese Communist annexation of Tibet in the twentieth century, the lack of impact from any sort of reformation or revolutionary movement has meant that the scholastic system has experienced no substantive alterations in thinking or styles of presentation since late medieval times. All of these factors make for hopeless confusion regarding where the borders that separate historical periods and domains of activity lie, contributing to a sense that "monastic debate " can be treated like a single, unitary province, within which one area can be used to make inferences or supplement lacunas in knowledge about another. The first step to a serious investigation of "disputation", therefore, is the recognition that it constitutes a specific activity, performed on the debate ground (whether in a medieval or contemporary setting), and as such must be distinguished from the "debate« of literature or that belonging to the aforementioned borderless realm.

In addition to the above confusion, questions must be raised about the way that scholarly writings relevant to disputation are read, as history. Illustrating this, we consider a key treatise by Sakya Pandita, entitled Entrance to Scholarship (mKhas pa la 'jug pa'i sgo), probably composed between 1220-1230: a work divided into three sections, one of which is devoted solely to, "the way to engage in debate ('bel ba'i gtam la 'jug pa). Thanks largely to Jackson's translation and analysis of this section, ${ }^{14}$ it is unfailingly cited by studies related to Tibetan scholastic work. Its relevance to medieval practice, although never entirely clarified, is always implied. I would summarise the questionability of this reading of such writings as follows:

1. Materials that are predominantly prescriptive in nature cannot be counted as evidence of action or behaviour: firstly, because that would rely on the idea that devotion to some religious figure meant that a community's compliance with whatever instruction emanated from that figure can be presumed - a presumption that academic studies of history must regard as unsound. Also, in the present case, this assumes that the practicalities of disputation performance were primary concerns for such figures in these writings, an assumption apparently largely contradicted by their content (see below).

The best-known text (the $R(w)$ a stod bsdus grwa) was composed by a Sangpu abbot ('Jam dbyangs mchog lha 'od zer, 1429-1500).

14 Jackson, Entrance Gate. 
2. Treatments of debate, such as those in Sakya Pandita's work, are largely contrary to those necessary for determining the conduct of an encounter (either a competitive or knowledgeseeking exercise) between groups or individuals in Tibetan monastic contexts, in that they use an expositional paradigm from a different historico-cultural setting, namely, that of early medieval India, the era of their source material (the treatises of Dignāga and Dharmakirti), which they comment on, and regard as authoritative. ${ }^{15}$ As such, disputation is conceived of as a confrontation between two individuals who follow, respectively, the tenets of a Buddhist and non-Buddhist "Indian" philosophical school. The encounter is viewed solely from the perspective of the Buddhist, whose primary task is to divest the opponent of his erroneous views, and thereby lead him to inferential realisation of various truths. Conception of the process is, therefore, premised on a power disparity between the two participants, such that correctness and outcome are predetermined. Purely on the level of principles, this is fundamentally incompatible with the structuring of monastic disputation.

3. Even in terms of prescription, if understood as providing guidelines or rules of engagement for disputation, what is presented in these works makes for unconvincing reading. As any number of examples from the worlds of games and sports, law, etc. attest, attempts to organise and institutionalise practices of contest that involve the formalisation of rules and codes inevitably exhibit signs of gradual finessing, with further stipulations added where existing regulation has been found wanting. These represent responses to and signs of engagement with real-world situations of exactly the form that is generally absent from Tibetan scholastic prescription related to disputation.

These points lead to a more important observation about the content of scholarly literature. Much is made of the fact that the aforesaid section includes comments in which Sakya Pandita appears to be critical of elements of disputation practices at Sangpu. ${ }^{16}$ The details he offers are scant, but he seeks to contrast them with what is stated in Dharmakirti's treatise Logic of Argumentation (Vädanyāya; rTsod pa'i rigs pa), one of a handful of medieval Indian Buddhist writings that discuss aspects of disputation practice. Sakya Pandita's criticism serves as a springboard for setting out his understanding of the principles outlined in Dharmakirti's treatise. But his main objection to the apparent steps of "Tibetan" process, is not so much that they contradicted those set out by Dharmakirti, but that Dharmakirti made no reference to such steps. Sakya Pandita fails to elaborate on what should replace the "flawed « Tibetan procedure, and indeed how could he, if the sources of authority that he was both bound to and bounded by included no real guidance on such matters? In this, he offers us an insight into the domain that a Tibetan scholar such as himself occupied. He thought of himself as someone whose chief role was to offer correct, faithful interpretation of canonical scripture and treatise. ${ }^{17}$ Debate may have been central to this role in that, following the traditions of scholastic literature, this "correct « interpretation could only be arrived at through

16 See Jackson, Entrance Gate.

17 Traditionally, this realm has been exclusively male. The personal pronouns used later in this article, when describing disputation practice, also reflect this. 
refutation of errant, rival interpretations. Thus, occasionally, engagement with disputation on a theoretical level proved necessary. ${ }^{18}$ But practical implementation of this theory, how disputation should actually be conducted within the Tibetan monastic context ... that was something that the scholar simply did not perceive to be his department! Indeed, remaining somewhat aloof from such mundane matters seems to have been judged as essential to the projection of a scholarly identity.

\section{Disputation and "the Language"}

Outside the realm of scholarly discourse on disputation conducted by figures such as Dharmakirti and Sakya Pandita, we must infer the existence of a parallel domain of action. This domain has undoubtedly been informed by the scholarly discourse, but investigation of that discourse does not itself constitute investigation of the domain, nor can that domain be reconstructed solely on the basis of that discourse's contents. Although recognising that disputation occupied a domain separate from that of scholasticism's written literature marks an essential step, it must also be acknowledged that certain features of structure and formulation that characterise Tibetan Buddhist dialectical exchange are common to both. But it cannot be assumed that the relationship with these features has been the same in both cases. Three such features seem especially pertinent here.

The first is the basic form of logical reasoning of the "Dignāga-Dharmakirti school «. ${ }^{19}$ Tillemans summarises this as: $" A A$ is $B$ because of being $C$, like $D$. More specifically, one invokes a logical reason $C$ to prove the truth of the conclusion $A$ is $B \ll{ }^{20}$ There are various technical details here, especially associated with the way that a relationship of a generalised nature, the so-called "pervasion" (Sanskrit: vyāpti; Tibetan: khyab pa), between C and B, which means anything that is $\mathrm{C}$ is $\mathrm{B}$, leads to knowledge of particulars; i.e. that $\mathrm{A}$ is $\mathrm{B}$. The important point though is that if the relations between the internal elements (C-A and C-B) are confirmed to be correct, they lead to the inference (that A is B), which constitutes indisputable knowledge.

The second, equally technical point, again summarised by Tillemans, relates to an important variant of the above:

... where the truth of $» A$ is $B$ « is not being established, but only the fact that it would follow from an acceptance (abhyupagama) of $A$ being $C$. Thus a debater can present an opponent with a prasariga (consequence) of the sort: »It would follow absurdly that $A$ would be $B$, because of being $C$. "Such a consequence will constitute the key step in a proof by reductio ad absurdum, a proof that will culminate in a type of contraposition, turning on modus tollens. When the pervasion in the consequence holds and the opponent understands that $A$ is not in fact $B$, the opponent will then be led by a "contraposition of the consequence (prasangaviparyaya, literally »reversing the consequence «) to understand that $A$ is not in fact $C$ because of not being $B .^{21}$

Tibetan authors largely followed the lead of Indian Buddhist treatises. The few writings on disputation relate to its theory. 
This second, consequence form of argument, "it would follow that A is B, because it is C " is, therefore, presented as a way of exposing the mistake in the opponent's thinking (within a thesis, argument, or assumption), but ultimately, with the aim of leading him to a correct inference. Thus, the framework of reference for discussions of these first two features is that of the Indian-treatise paradigm, mentioned above.

The third feature is a more general one. Despite the aforementioned preference for describing disputation in terms of the aforesaid paradigm, where Buddhist is pitted against non-Buddhist, it has also proved necessary to develop a way of representing encounters between Buddhists. "Internal« disputation is overwhelmingly depicted as an irenic exercise. Inspiration is taken from influential canonical works, such as the Sutra Elucidating the Intention (Ärya-samidhi-nirmocana-sütra), which is structured as a series of dialogues, mainly between the Buddha and various spiritually advanced bodhisattvas. Through dialectical exchanges, the apparent inconsistencies in earlier teachings given by Buddha are resolved, primarily by expounding a complex hermeneutic (related to differing audiences and abilities), and thus revealing the Buddha's real (entirely consistent) intent. In the high-minded sense, all »internal« dialectical exchange purports to work towards the resolution of perceived inconsistencies arising from (mis)interpretation of the written canon, but as elaborated below, there is a more immediate sense in which this "inconsistency resolution" approach enters into disputation.

All three features have roles in or exert some influence on the structure of Tibetan Buddhist dialectical exchange. Previous studies have generally considered the first two in terms of what amounts to a "logical method«. This connotes a technique of analysis, designed with the aim of producing some form of result or conclusion. This is exactly how dialectical exchange is depicted in scholarly literature, but it cannot be assumed that disputation sets itself the same goal. In terms of beginning to understand the evolution of disputation as a practice (distinguished from dialectical exchanges conducted in written literature) the matter is better approached, I believe, by concentrating on the mode of communication, what is henceforth referred to as "the language « of dialectical exchange. ${ }^{22}$ The language is primarily a medium or vehicle of expression, with its own structure and rules. Just as with other languages, where grammar, phonotactics, etc. guide and limit what can be said, features in this language circumscribe communication. Aspects of the logic or logical method developed by Dignāga and Dharmakirti may be embedded within and conveyed by the language, but they must be distinguished from it, and it is the language, and more particularly, the extent to which its usage has been insisted on or enforced, that is more relevant to understanding the institutionalisation of disputation practice.

Academic discussion in this area is regularly framed around issues of origin and authority; attempts to identify the Indian source of various Tibetan traditions (from which they may be seen to derive their credence and authority), and judge how loyal Tibetan scholarship has been to the Indian Buddhist heritage. Discussions about the consequence variation, for instance, invariably refer back to the Indian-treatise paradigm, concerning themselves with matters of logic and epistemology (in the production of inferences) and how the consequence

22 Neither »language« nor »method « represent indigenous descriptions here, there being no terms for the phenomenon discussed. 
might be related to different Indian philosophical schools. ${ }^{23}$ Such discussions are, at best, tangential to the consequence's actual employment in Tibet. But as with the Sakya Pandita example above, the focus on it illustrates how attention from domains of historical practice (such as disputation) is constantly deflected into discussions related to the "higher order" that is supposed to govern action (and is to be discovered within the authoritative text).

Purely in terms of understanding the Tibetan medieval culture of disputation, it is necessary to recognise that institutionalisation involved different levels and steps. The establishment of the language as the convention, the norm of communication for dialectical exchange, represented one such level. But the formalisation of practices, specifically disputation, which used that language, was another, as was the creation of monastic institutions, in the form of physical and organisational entities, that might house or manage such practices. Popular tradition credits Chapa Chökyi Senge with introduction of the consequence format onto the debate ground. To state it clearly, this suggests that he was the first to lift a logical formulation found in Indian scholastic writing and adapt it for practical use in formal disputation. Contemporary medieval sources offer no conclusive evidence regarding Chapa's precise role in the process, nor about the nature of Tibetan dialectical exchange prior to this reported innovatory move. But this introduction of the consequence meant the creation of the language, and it seems likely that the institutionalisation of both the language and the practice of disputation occurred in tandem, primarily at Sangpu. The introduction of the language provided structure to dialectical exchange, by demanding that an argument be formulated according to the single A-B-C pattern of elements. The grammatical rules governing this language dictate that the elements (together with their functions) be distinguished and indicated by suffixes and word order. ${ }^{24}$ This gives tremendous concentration and focus to arguments, while simultaneously severely restricting the nature of exchange organised around them. Dialectical discourse can neither be open nor follow a straightforward question and answer format. Instead, it assigns each interlocutor with one of two roles: that of challenger or respondent. The challenger's role is to criticise the respondent's position, rather than explicitly setting forth his own, and to do this in consequence form; i.e. "It (absurdly) follows (from your assertion) that $A$ would be $B$, because of being $C$. "The respondent, for his part, must answer in terms of the structure presented to him. The desperately small set of mono- and disyllabic responses available allow him only to indicate whether he either accepts the challenger's consequence (and thus, concedes his own position is flawed), or rejects it, but the latter can only be on the grounds that either the relationship C-A or C-B is not fulfilled. The respondent is likely to reject the consequence, at which point the challenger, rather than introducing a fresh line of argument, will set about establishing the disputed relationship, hoping, thereby, to prove that the conclusion contained in his original consequence was correct.

23 I chiefly refer here to the distinction between the Svätantrika and Prasangika, the supposed Indian sub-schools of the Madhyamaka ("Middle Way") school of Buddhist thought. Although usage of consequences is presented as the main issue, the philosophical positions that underpin this usage are the real area of interest in these discussions.

24 These markers take the form of suffixes, attached immediately following the content of each element. Thus, chos can (A); phyir (C); thal (B-consequence); te/ste (B-logical reason). 
That outlines the basic form of the language and the kind of exchanges that it permits. But the real question, historically, is the extent of its usage and impact in different domains. Throughout the medieval period, in the field of scholarly writing, we observe a growing reliance on the language: it, just as much as content, seems to have been understood as defining the literature of scholasticism, and the two (language and content) were increasingly seen as inseparable. By the fourteenth century, texts constructed almost entirely of the language appear, and there is a clear sense that formulating arguments (refutations, assertions, etc.) in terms of the language had become a prerequisite for serious scholarly exchange. The notion of »exchange" in literature is a loose or even artificial one; these writings were the author's imagined interaction with his opponent(s). Nevertheless, this growing dependence on the language cannot be seen as isolated from what was happening in the realm of disputation.

\section{Disputation Practice, Institutionalised: The Post-Medieval Manifestation}

Having moved discussion out of the realm of the abstract, we now concentrate on trying to understand the practice of disputation in institutional and historical settings. Firstly, we consider disputation in relation to the Geluk school, a context that encompasses current practice but, historically, begins in the centuries just following the medieval era with which we are concerned.

Ever since its inception in the fifteenth century, the Geluk has been an overwhelmingly monastic school, with scholasticism at its heart. It eventually rose to religious and political dominance following the establishment of the Ganden Phodrang ( $d G a$ ' ldan pho brang) administration in 1642, by the Fifth Dalai Lama, backed by Khoshut Mongol forces. Geluk power was concentrated in their main monastic centres, especially the »three seats «, founded in the early decades of the fifteenth century, close to Lhasa. As centres of education they drew heavily from Sangpu traditions, placing considerable emphasis on disputation. By no later than the seventeenth century they were the largest monasteries in the world, housing thousands of monks, either actively engaged in or playing supportive roles (clerical, manual, etc.) to the educational system followed there, the successful culmination of which led to a final examination and the awarding of a scholastic title. The rise of the Geluk was accompanied by the solidification of religious identities - both the formation of religious denominations and friction between them. Disputation's increasing association with the Geluk system meant that it took on symbolic significance: what for those in the Geluk school was an emblem of educational and intellectual rigour, was for others, resentful of Geluk religious and political domination, an object of criticism. ${ }^{25}$ Disputation has, consequently, occupied a prominent place in the religious imagination within Tibet, but equally, perceptions of it have been coloured by competing, and ultimately, sectarian-inspired views.

25 The perceived overemphasis on debate and the scholastic approach is regularly criticised by those who favour more contemplative approaches to religion, as well as those who favour a broader spectrum of learning activities. 
Moving from these observations regarding the historical place of disputation to specifics of current practice, disputation is seen as serving the purposes of an educational system. ${ }^{26}$ It is judged necessary for students to learn about the contents and to tease out the issues dealt with in a text. The dialectical process, in which students are compelled to adopt opposing sides, it is believed, represents the best way to achieve this, and results in deeper engagement with the text. Disputation, therefore, is the main educational activity, which students engage in for many hours each day. The dialectical language has major strengths. It is designed to ensure that positions are clearly expressed and that exchanges remain focused. It also allows for transparency and scrutiny of the exact line of reasoning leading to a particular conclusion. Its stark representation appears to deny the possibility of vagueness, obfuscation, evasion, or even the deployment of rhetoric. Theoretically, it would appear to be a tremendous asset, from which dialectical exchange must benefit. Shortcomings might seem to derive more from the strictness of its application. Current Geluk practice insists that disputation be conducted through the medium of the language and that participants adhere to their assigned roles. The respondent may never, therefore, be given the opportunity to articulate his position fully, whereas the challenger, whose role it is to hurl effective criticisms, need not voice his own. Learning how to exploit the language is, furthermore, relatively easy, despite its limited range. The skilled respondent finds ample opportunity to retreat behind the few responses at his disposal, holding rigidly to a particular position that he might find impossible to justify were he forced to spell it out. But more especially, the language and technique allow the challenger to exploit the hazy divide between positions that the respondent actually holds and those that might be ascribed to him, based on logical entailment. Various factors, including the single-minded conviction in the efficacy of disputation, the ethos that surrounds it, the students' desire to perform well, and the fact that the activity is largely unsupervised, all significantly shape the practice. Perhaps unsurprisingly, disputation is a highly competitive contest, where skill in technique may prevail over knowledge and understanding. The skilled challenger is one who knows how to set a trap, the skilled respondent is one who anticipates such a trap and takes evasive action. The main pressure in the exchange is on the respondent, whose role is regarded as the more demanding. He is given no time for considered answers. The challenger fortifies his interrogation with stylised but aggressive gestures. Exchanges build to a crescendo and are conducted at breakneck speed. On the debate ground, particularly in the larger gathering, where one or two monks must respond, amid crowds of actual or potential challengers, the atmosphere is invariably boisterous and often uproarious. Although the medium of the language largely disbars rhetoric and the arts of persuasion from the disputation format itself, banter and humorous asides frequently accompany it, particularly before a large, appreciative audience, where either party might feel that his position would be "enhanced « by some witticism, at the expense of the opponent. In brief, we must refer not simply to the practice of disputation, but a whole culture that has grown up around it.

26 In this section of the article my observations are based on my own experience of involvement with the practice of disputation. 
While the Geluk may have what some regard as a unique obsession with disputation, it is also practised in many non-Geluk monasteries, following the same format as in the Geluk centres. It is possible, therefore, to identify a basic schematic template to which current Tibetan monastic disputation generally conforms:

\section{Opening}

$\mathrm{C}$ (the challenger) quotes a passage (often just a few words) from a text

$\mathrm{R}$ (the respondent) must identify, locate (in the textual scheme), and interpret this

$\mathrm{C}$ introduces the dissonant element, in a consequence form: »it follows that $\mathrm{A}$ must be $\mathrm{B}$, because of $\mathrm{C} \ll$

\section{Body}

$\mathrm{R}$ disputes either of the two relationships suggested in the consequence

$\mathrm{C}$ reformulates a consequence, to establish the correctness of that relationship

$\mathrm{R}$ again disputes a relationship

C reformulates, accordingly

As above, etc.

The dissonant element is another passage or a line of reasoning that appears to clash with C's interpretation of the original passage. Thus, distantly or rhetorically, the process references the irenic, »inconsistency resolution" approach mentioned above. But here the two roles within the exercise resemble those of prosecutor and accused in an adversarial system. As such, the dissonant element is presented not so much as a conundrum, but as a contradiction; one that the respondent is, ultimately, guilty of introducing, and the challenger is tasked with exposing. Ostensibly, the whole disputation proceeds from this original "contradiction", and involves the challenger attempting to extract an admission of guilt from the respondent, by blocking off all logical escape routes, and forcing him to agree with the challenger's first consequence (something that the respondent must, at all costs, avoid).

In reality, however, disputation is a more wide-ranging and creative process than this basic structure suggests. No self-respecting respondent would submissively concede. In pursuit of his case, the challenger must construct various chains of reasoning. It is through the reversal of these that he hopes eventually to lead back to the first contradiction. If the chains and alleged links set out during a well-structured argument were represented graphically, they would resemble an intricate structural configuration. But only part of the disputation is taken up with the original contradiction. The challenger develops various side-arguments, touching on other issues, and seeks to entangle the respondent in these. None of this would be possible if the consequence here were simply a reductio ad absurdum logical method or tool, and indeed its relationship with a scholastic method or process of inference is tenuous at best. Even determining whether or not an individual consequence is correct, according to the stipulations of the scholastic treatises, may have limited relevance, as the frenetic pace that exchanges are conducted at militates against careful deliberation. Here, the consequence helps maintain the exchange's coherence, by creating the impression that all the challenger's arguments and lines of reason somehow "follow « from the respondent's position. But as the challenger's main means of communication, it cannot simply serve as a vehicle for reductionist logic or the sort of deductive argument that this implies. It must accommodate all manner of argument, statement, assertion, speculative comparison, and segue. Moreover, although the language dominates proceedings, the degree to which it is enforced is the chal- 
lenger's prerogative. Although he often, stridently, demands its usage, he sometimes invites his opponent to step outside its framework, to explain his position. It is, therefore, possible to create a space for more open discussion (although in presenting the respondent with such an opportunity, the challenger is only probing for new lines of attack). Hence, despite the apparent rigidity of the process and all the pressure that the structure and occasion are designed to place on the respondent in particular, disputation fosters a degree of creativity and does not exclude all possibility of unstructured exchange.

The starting point for disputation is the accusation of contradiction. As such, it might be expected that the process yields some result regarding that issue. What might seem the most likely scenario, in which the respondent makes a fatal error (causing a collapse in his position) is, in fact, something that can rarely be agreed on to have occurred, not least because there is no third-party role or any mechanism that might lead to any conclusive decision. In fact, we may go further, and say that resolution is antithetical to the process. This is dissonance as procedure; the challenger is obliged to find fault with whatever the respondent says. This represents what can be considered a fundamental tension within disputation practice. The rhetoric behind the engagement largely matches the ends towards which the participants' energies appear to be devoted; everything seems geared towards resolution. But not only is there no procedure in place to reach that end, both parties would be seen to have failed in their respective roles if they ever arrived at such a point. The dissonance here is contrived, conjured up solely for the purposes of the exercise. Similarly, the positions that each party commit themselves to, and whatever they say in pursuit or defence of those positions, have no validity beyond the session of the disputation in which they occur. But both participants must be seen to perform their roles, and as such, are united in their opposition to resolution. The exercise may be absorbing, intellectually stimulating, and edifying, but it is potentially an endless one, producing no judgements or final conclusions.

Disputation is more than important to the system of the large Geluk monasteries, it is something that pervades its institutional structures. Disputation serves as the main pedagogical method within the model of education in the Geluk centres, which could be described as ultra-heuristic: one learns through mainly unsupervised disputation. Disputation technique, which is highly specialised, is not learnt formally, in classrooms, but through observation and engagement on the debate ground. Large groups of participants are considered vital for this. Until recent decades, the examination system also centred entirely on disputation: performance in public disputation "finals « was the basis for the awarding of scholastic titles. Such titles became requisite for official advancement within the system of these centres, something necessary for appointment as abbots, administrators, teachers, and disciplinarians, and also opened the way to placements and positions outside the centres. Officialdom became increasingly involved in the examination process, particularly in its efforts to ensure that the premier titles went to those who acquitted themselves best in the final disputation. With performance in this domain becoming almost the sole measure of success and means of advancement, there seems to be evidence of an institutional loop, in which disputation has gradually been allowed to shape the whole system. This loop might also be said to contain certain vortex-like tendencies, gravitating towards progressive concentration. 


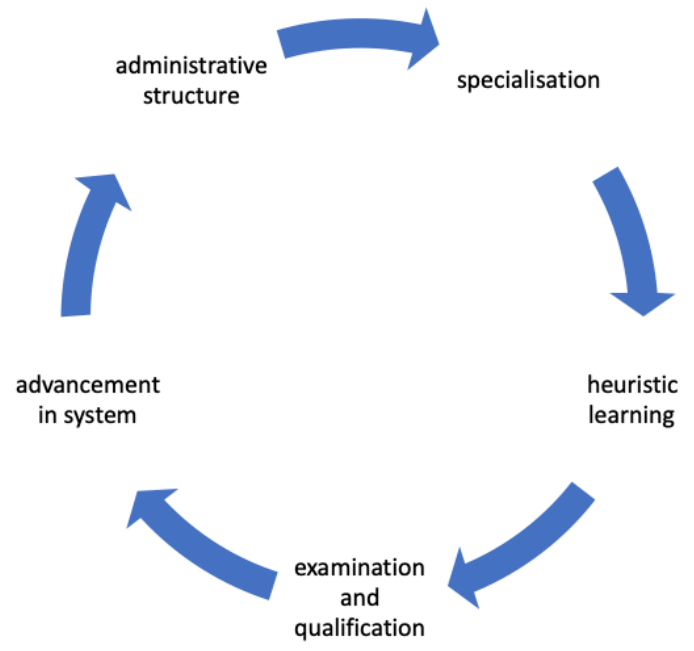

Although it should also be remembered that certain aspects of Tibetan scholasticism display an extraordinary degree of resilience and continuity, no direct inferences can be made about medieval practices based on these observations of the Geluk system. The Geluk ascension must, primarily, be understood as a post-medieval phenomenon, intertwined with the foundation of state. Nevertheless, these observations seem pertinent to understanding the medieval practice. Firstly, this is a striking example of what could be described as the "logical outcome " of an unimpeded movement along an institutional trajectory. However important to medieval scholasticism disputation might have been, it was nothing like as central as it became in the later Geluk system. No detailed picture of the incremental steps that led to this centre-staging yet exists. But notwithstanding minimal "state« intervention, aimed at greater standardisation and quality control at upper levels of examination, the development of the Geluk education system apparently proceeded largely unchecked by outside or countervailing forces. The Geluk school's successful alignment with the state benefitted it temporally and boosted the popularity of its educational centres. Rather than broadening intellectual engagement, the growing confidence in its institutions seems to have prompted insularity and inversion, with an increasingly narrow focus on disputation as a technique and a means in itself. The practice of disputation became the monastic centres' raison d'être and the basis of their identity. But crucially, the fundamentals that the later Geluk system concentrated on and rigorously applied were those it had inherited from medieval scholasticism; namely, a conviction in the efficacy of formal disputation and reliance on the language.

Secondly, viewing disputation within the Geluk system supplies a much-needed alternative perspective on the aims and motives behind the practice. Debate, more generally, has been depicted as something that sets itself religious and/or intellectual goals. Understanding disputation within an institutional setting presents a counter-voice to such narratives. As illustrated, the principal ends served may be those of the institution. Disputation can become a form of ritualised behaviour: the motives for engaging in it can be created by the institution itself, with the logic primarily being that of self-perpetuation. The Geluk example may be a uniquely extreme one, but the extra dimension that it brings to the understanding of disputation, in which it can be viewed in terms of institutionalised practices and behaviour, and whatever motives might be associated with them, is an invaluable one, which might have relevance to the medieval practice. 


\section{Medieval Disputation, in Practice}

With the benefit of the greater clarity that the foregoing discussion has hopefully provided regarding issues of institutionalisation, we return to the question of what can be learnt (particularly given the limited nature of the primary sources) about disputation practice in medieval times, especially the period between the late thirteenth and early fourteenth centuries (the point just prior to the rise of the Geluk) when a more open form of scholasticism flourished.

An additional challenge in dealing with historical sources in this area, alluded to above, is that Tibetan scholasticism seems never to have developed a nomenclature or formal language for describing disputation or its processes. Terminology lifted from the Indian-treatise paradigm occasionally appears but is patently »foreign « to the Tibetan practice. This absence cannot be seen as evidence that disputation was a rare or relatively unimportant practice. It is simply a curious feature of Tibetan scholasticism, as corroborated by the current tradition. Thus, while the content of disputation, including the religio-philosophical subject-matter of Buddhist treatises, and especially the varieties of correct and fallacious logical reason that are preserves of the logico-epistemological tradition, have been subject to incessant categorising and taxonomical ordering, the same mentality appears never to have been applied to the process itself. Indeed, the conceptual and linguistic means of stepping outside the process to describe it barely exist; there is no language for expressing the stages, sequences, or forms of interaction within the practice, but even for such basics as "disputation " and "challenger", there are no agreed designations. This disjuncture complicates attempts to understand the evolution of disputation formats. It might also seem to deprive us of knowledge of the process's intended ends, enshrined, as it were, in procedure. Hence, we find nothing comparable with the solutio (final solutions) or, in the early medieval European universities, the determinatio (summing up), which consummated the disputatio ordinaria, indicating that disputations were presided over by a master, who would issue some form of judgement regarding the opposing arguments, ${ }^{27}$ and that settlement and resolution were deemed intrinsic to the activity.

Regarding what can be seen as the Tibetan practice's province of application: unlike in medieval Christian and Islamic scholastic traditions, there is no real evidence of any branching out into other fields. Law was never a scholastic discipline; medicine developed into one, but intellectually, the logical method does not seem to have been regarded as relevant to it. Neither are there signs of other fields benefitting from the skills and techniques cultivated on the debate ground. But even within the context of scholasticism, disputation seems only to have been employed in rather specific areas. As the medieval tradition developed the ideal of the monk-scholar, notions of which areas such an individual should have knowledge or mastery of were gradually formalised. Topics pertaining to the literary arts, the esoteric (tantra), and, to a certain extent, medicine, astrology, etc., did not belong to what eventually became the official scholastic curriculum, but knowledge of them was expected. None of these topics, however, were regarded as falling into the domain of disputation. The aforesaid curriculum was gradually organised around certain treatises within the large "canon« of 
Buddhist treatises translated from Sanskrit, dealing mainly with religio-philosophical matters. The treatises that the scholastic tradition finally determined should form the essential core were limited in number. Disputation seems to have focused almost exclusively on these. Indirect support for this is found in patterns of scholastic writing: commentarial works on the favoured treatises became both more numerous and decidedly more dialectical in character, suggesting something of a symbiotic relationship between the scholastic spheres of composition and disputation. The later Geluk school's conception of which topics and texts are "fitting " material for disputation largely accords with that which emerges from medieval sources, suggesting that despite holding these concepts in a more fixed way, the school has basically inherited them from the earlier tradition. ${ }^{28}$ All the evidence, therefore, supports the idea that medieval scholasticism, at a relatively early stage, carved out a very clearly defined territory for disputation. This may well be seen to have implications regarding the practice's perceived use (and intellectual horizons). Whatever the exact story of disputation's development at Sangpu (including the role of Chapa and others in formalising the practice, introducing the consequence format, and thereby creating the language), its pedagogical potential appears to have been realised immediately. In post-medieval times, there are no obvious signs of formal disputation being practised outside the educational setting. This intimate relationship with education could lead one to wonder whether it might both have been designed for and never really ventured beyond the boundaries of institutional learning.

For at least partial answers to this question we may turn to an invaluable document containing evidence of medieval disputation practice. This is the "record of disputationexchange« (rtsod yig), produced immediately after an encounter that occurred c. 1390, at Sakya monastery, between the celebrated scholar Rongtön Sheja Kunrig (Rong ston shes bya kun rig, 1367-1449) and the almost anonymous Tukje Pel (Thugs rje dpal, dates unknown). ${ }^{29}$ This may represent a unique example; the only one of this variety of document to have survived from medieval times. It refers, frustratingly, to a variety of institutionalised practices related to disputation (including the official recording of exchanges) for which we have no other complete primary source. This encounter did not occur within the context of education, and neither participant was affiliated to the monastery that hosted it. Instead, contemporary writings indicate something of a custom during the decades in question of established scholars being invited or challenged to engage in public disputation, within the confines of various scholastic centres.

28 The exception here is tantra. Study of the area was increasingly institutionalised in the Geluk system, although outside the main scholastic centres.

29 A reproduction of the manuscript, together with a later published version of the text, appears in Huang, Record of a Tibetan Medieval Debate. Citations here refer to the MS version. 
Although the document cannot be analysed in depth here, highlighting a few key features relating to the structure and format of the exchange, rather than its content, will serve to illustrate similarities with the pattern of later practice outlined above, but also some significant differences.

\section{1) Opening}

a. Tukje Pel sets forth his position or »thesis«, then challenges his opponent to argue against it

b. Rongtön presents seven consequences, each derived from and revealing what he proposes is a fault in Tukje Pel's position

2) Body

a. Tukje Pel responds to each, in turn, with:

i. A parallel refutation

ii. An actual response

b. There are occasional follow-ups and counter-responses

c. Rongtön questions Tukje Pel's hermeneutic model

d. Looser exchanges follow, with clarifications, criticisms, and responses

Tukje Pel's position is the stance he takes on a particular point of scriptural interpretation. He refers to this as his damcha (dam bca'), for which the translation "thesis " seems justifiable. The same term crops up in relation to the opening section in current practice, where a "root-damcha " (rtsa ba'i dam bca') is that point that the respondent cannot concede without seeming to admit defeat, and from which the whole discourse essentially proceeds. But there, "thesis" seems inappropriate, as this root-damcha denotes little more than a point or position that the challenger, by introducing the dissonant element, has manipulated the respondent into accepting or simply decided to attribute to him. By contrast, Tukje Pel is clearly setting forth his own views and, unlike his latter-day counterpart, is allowed to express these at some length, formulated not in the language, but as a minor discourse. Some of Rongtön's seven consequences resonate with later use of the dissonant element, in that the faults they refer to are simply purported clashes with certain passages of scripture. Both parties seem pre-prepared for the encounter, generally familiar with their opponent's position, and there is some indication that Rongtön may be presenting a set of stock criticisms of positions such as that held by Tukje Pel.

In the body of the disputation, where the interaction between the two parties is more meaningful, the exchanges are relatively personal, free-flowing, and apparently impromptu. Although the respective roles of Rongtön and Tukje Pel are, ostensibly, those of challenger and respondent, there are no signs that this is used or perceived to create additional pressures or limit what either party might say. The respondent, notably, is permitted to clarify and expand on his position, and protest at what he feels is its misrepresentation. The way that the disputation is ordered, with seven (critical) consequences and seven responses, has an interesting effect on the structure of exchanges. It creates self-contained sections or units of discourse. Thus, each criticism is dealt with independently of the others. The sections vary in length, apparently depending on Rongtön's feeling about Tukje Pel's answers: Rongtön seems keen to pursue some of the responses, offering counters to them, leading to prolonged exchange, but he shows no interest in others, meaning that the exchange on them is curtailed. In each section, the discussion runs its course, ending without any formal conclusion. 
This effective compartmentalisation of each discussion, and the issue it deals with, means that there is simply no opportunity for the exchange to be dominated by an endless stream of consequences or dogged pursuit of a single point. Similarly contrasting with current practice, this process concerns itself with the soundness of the personal, and seemingly committed stance, of a mature scholar. Procedure and technique do not govern or obscure what is an authentic and open exploration and exchange of ideas. In these regards, this could be said to conform to many peoples understanding of a »disputation«.

In spite of the aforesaid differences from contemporary practice, this exchange still speaks of a high degree of institutionalisation. Firstly, notwithstanding the fact that while both at the outset and in some of his "actual answers " (lan rnal ma) Tukje Pel is allowed to describe his thinking, generally, the exchanges in this encounter rely heavily on the language. There is a strong sense that it is only when positions, issues, and criticisms are formulated in and communicated through it, that they can properly be expressed and scrutinised. Furthermore, for all the relative openness of the exchange, the participants are obviously so accustomed to usage of the language that the urge to formulate their thoughts in terms of critical consequences is one that they seem unable to resist.

Secondly, although the seven-consequence structure means that this is not a disputation dominated by singularities, it nevertheless results in a highly structured exchange. Tukje Pel employs a two-pronged approach to rebut each of Rongtön's critical consequences. His "actual response" is preceded by his "parallel refutation " (mgo mtshungs kyi dgag pa), issued in the form of a counter consequence, exposing an alleged fault in Rongtön's own line. It is unclear whether this systematic treatment of Rongtön's criticisms represents the standard practice of the time or Tukje Pel's own choice. There is nothing comparable in current disputation, where, as already remarked, the respondent has little significant right of reply. However, the two-pronged approach, phrased in exactly the same terms, appears in scholastic writings from the medieval period in question, suggesting that its usage for structuring dialectical exchange was more widespread, and that this might have formed part of an established disputation practice.

Thirdly, the document reveals a more surprising aspect of disputation. Reference has already been made to the role of banter in current practice. Joking here is "agonistic «, ${ }^{30}$ and made at the opponent's expense. But equally, debate-ground humour has other important performative and entertainment dimensions, and on a psychological level can function as a tension-release mechanism. It could also be remarked that what has been described as Tibetan "polemical writing" refers to that in which scholarly authors, railing against the views of some religious opponent, resort to ridicule or outright insult. In either case, abuse, in its various forms, directed against the opponent, is generally understood as peripheral to the serious business; that is, discussing the participants' views on religio-philosophical matters. The record of Rongtön and Tukje Pel's disputation contains numerous exchanges in which each party seems, to put it mildly, to be less than charitable about his opponent - something that, following the common pattern of interpretation could be judged as tangential to the »real« discussion. But why record these comments at all? Can their inclusion be attributed to 
over-officious or dutiful clericalism? This seems extremely unlikely, given the careful process that the document's colophon informs us went into its preparation. The most plausible explanation is that the comments are included because in the minds of all those involved, such exchanges represented as much a part of the disputation as the aforesaid "substantive" content. Closer scrutiny of this material appears to confirm this. These are not offhand quips or angry outbursts, but a series of structured exchanges, following predetermined conventions. They either take the form of apparent direct insults (where the opponent may be described as »blind « or "an ox"), ${ }^{31}$ or a self-composed verse, in which the speaker either a. makes personal boasts, or b. ridicules his opponent. As with the shouting and physical gestures of current disputation practice, an outsider might easily judge these to be needlessly aggressive or incongruous with a religious exercise. But such superficial judgements necessarily fail to grasp the ritualised nature of what are, literally, exchanges, set within strict parameters. Such interactions are disciplined and measured. Their content never goes beyond a single theme, the respective reasoning abilities of the two parties, and however abrasive, exchanges are always limited, mainly to one comment per participant. Each delivery invites a response. The implied question, particularly with the verses, seems to be, „Can you match this? « The other party always accepts the challenge, and his response corresponds with the original in form (i.e. verse for verse), general content, and use of imagery. Ideally, he redirects the import and imagery of the original back at its source, with the addition of some humorous twist that mocks the initiator of the exchange. This is clearly a ritualised, verbal contest, with correspondences to medieval flyting, or modern-day freestyle rap battling. Verse trading does not feature in current disputation practice, but in other regards the historical and contemporary forms of Tibetan disputation seem to work from the same (unwritten) rulebook, employing the same techniques, figures, and often even the exact same insults.

\section{Conclusion}

By seeking to gain a better understanding of three areas identified towards the start of this article -1 . The relationship between scholarly literature and practice; 2 . The form of medieval disputation; 3. The practice's purposes and aims - my main intention has been to stake out a separate territory for and indeed assert the existence of a Tibetan medieval practice of disputation, something that has not been undertaken before. To achieve this, I have argued for the need to delineate borders within the loosely defined sphere of »Tibetan religious/ monastic debate«. Partly arising from confusion pertaining to that sphere, when faced by the considerable gulf that appears to separate disputation as currently practised from what is discussed and represented in scholarly (largely medieval) writings, some are tempted to attribute this to something that has occurred within the Geluk system, such that as the practice was increasingly turned towards serving educational ends, it might have been diverted from its original purpose, perhaps suffering some form of debasement through institutional ritualisation. The chief problem with the perceived gulf, and naïve endeavours to reconcile it, is that they involve comparison of a practice with what is essentially an ahistorical construct, namely, some notion of disputation that draws from the familiar, abstract domain of 
logical structures and principles, as well as the textual world of canonical sources and religious pronouncements, but has no demonstrable relationship with any actual practice. The exact connection between scholastic dialectical writings and the practice of disputation is neither a self-explanatory one, nor one that can be understood simply by assuming a necessary relationship between content, prescription, and performance.

Having discarded that flawed comparison, this article has concentrated on one between current and medieval disputation practices, as far as such is possible. The highlighting of the ritualised side of current practice is not part of some crude attempt to craft, contradistinctively, an idealised vision of medieval practice, one that necessarily, as with the flawed comparison above, ends up ascribing to these practices a higher set of religious and intellectual goals and motives, occupying a realm that is inaccessible to us. At the same time, it cannot be denied that the practice represented in the »record «, as in other, more fragmentary primary sources, appears less rigid, more open, and crucially, interested in the articulation and exploration of genuinely held positions. In that sense it seems to have characteristics redolent of an authentic process of intellectual exchange; something that would probably be interpreted not simply as a divergence in form from current practice, but expressive of a differing set of concerns, purposes, and aims. For ultimately, this might be seen as the crux of the issue: what lies behind the creation of such a formal structure of disputation and what accounts for its continuing popularity? As the Geluk example shows, these should be treated as two separate questions: what motivates engagement in a practice within a long-established institutional setting may be quite different from what motivates the practice's original creation (however much those performing the former evoke the spirit of the latter).

Medieval sources inform us that formal disputation had at least two iterations: the first, educational, including as a means of examination, and second, the form of organised scholarly skirmish, such as represented in the "record«. In terms of motives and goals, the more appealing idea might be that the first grew out of the second; that educational practices came to model themselves on a pre-existing forum of scholarly discourse. But thinking in terms of the practice's formalisation, if anything, the reverse seems far more likely. Although historically, looser forms of scholarly exchange predated formal disputation, the practice was specialised enough to require training to engage in it. Thus, those who engaged in the practice were products of an educational system. The notion of a practice co-opted for educational purposes seems unrealistic. Institutionalisation was not introduced into, but rather created disputation: practice is institution. This manifests most markedly in the creation and usage of the language. The different spheres of Tibetan Buddhist dialectical exchange and those who have participated in them are united not so much by an affinity of usage of the language, but, as already noted, the apparent conviction that it has represented the sole means by which an argument could be clearly formulated and subjected to scrutiny. As such, its usage has been seen as the most basic rule of engagement, and the ability to think and express oneself in this language can be viewed as inseparable from the mentality of scholasticism.

Analysis of medieval sources on disputation seems to lead less to peeling away layers of institutional practice than to discovering those of which we had previously been unaware. The "record «, it must be remembered, was preceded by several centuries of disputation practice: plenty of time for the accretion of layers that might subsequently have been shed, such as certain features of argument structure, or the ritualised trading of insults and verses. Such a process of accretion seems the most likely source of what I have referred to as the fundamental tension in current practice. The need, at all costs, to keep the process going, and never reach a resolution must certainly derive, to a considerable extent, from the educational setting. The 
heuristic model was able to accommodate large numbers of students in that it centred on the low-maintenance (i.e. mainly unsupervised) practice of disputation but could only succeed in doing so as far as it was able to inculcate a culture and psychology of self-sustaining activity.

Linking back, finally, to the all-important question of aims and motives, despite the fact that the current unremittingness of disputation probably derives largely from the later setting, and seems unlikely to have been so pronounced in medieval disputation, this does not mean that its introduction or amplification brought about a "loss of resolution«. We may be certain that in medieval times, the practice was regarded as a supreme method of exposing the views and arguments, together with their advocates and detractors, to public scrutiny. But the absence in the record of any reference to a final outcome of the process, in the form of a decision, judgement, ruling, or solution, is reminiscent of current practice. In fact, while the theory of such things is discussed in works such as Dharmakirti's Logic of Argumentation and Sakya Pandita's Entrance to Scholarship, it is far from clear whether this has ever been a feature of disputation practice in Tibet.

Pending further investigation of this matter, it does at least provide us with a thought-provoking note on which to end: Tibetan disputation shares some compelling affinities with European medieval practice. The latter's general aim of resolving issues pertaining to interpretation of scripture, its evocation of auctoritas, and its employment of dissonantia, among other things, strongly resonate with elements of Tibetan disputation. However, the idea of a practice that perhaps matches those of other medieval systems in terms of rigour and exceeds most in terms of the acuity that it brings to issues and arguments, but might not have been designed to reach some form of conclusion or resolution would, I suggest, seriously challenge certain common assumptions and expectations, and perhaps also pose some interesting questions about our understanding of the medieval mind.

\section{Acknowledgements}

I wish to express my gratitude to Professor Birgit Kellner and Dr Pascale Hugon for the invitation to participate in the "Rethinking Scholastic Communities across Medieval Eurasia III" workshop, at which I delivered the paper on which this article is based. Work on both was undertaken as Junior Research Fellow, Tibetan and Himalayan Studies, at Wolfson College, University of Oxford. I am indebted to the college, the Tibetan and Himalayan Research Cluster, and especially to Professor Ulrike Roesler. I also wish to thank Dr George Fitzherbert for the part he played in creating the fellowship. 


\section{References}

Cabezón, José, Buddhism and Language: A Study of Indo-Tibetan Scholasticism (Albany, 1994).

Cabezón, José, Scholasticism: Cross-Cultural and Comparative Perspectives (Albany, 1998).

Dreyfus, Georges, The Sound of Two Hands Clapping: The Education of a Tibetan Buddhist Monk (Berkeley, 2003).

Dreyfus, Georges, What is debate for? The rationality of Tibetan debates and the role of humor, Argumentation 22/1 (2008) 43-58.

Huang, Chun Yuan, A Record of a Tibetan Medieval Debate: History, Language, and Efficacy of Tibetan Buddhist Debate. Unpublished $\mathrm{PhD}$ thesis (Harvard University, 2014).

Hugon, Pascale, Enclaves of learning, religious and intellectual communities in Tibet: The monastery of gSang phu Ne'u thog in early centuries of the later diffusion of Buddhism, in: Eirik Hovden, Christina Lutter, Walter Pohl (eds.), Meanings of Community across $\mathrm{Me}$ dieval Eurasia: Comparative Approaches (Leiden, 2016) 289-308.

Jackson, David, The Entrance Gate for the Wise (Section III): Sa skya Pandita on Indian and Tibetan Traditions of Pramāna and Philosophical Debate, 2 vols. (Vienna, 1987).

Lempert, Michael, Discipline and Debate: The Language of Violence in a Tibetan Buddhist Monastery (Leiden, 2012).

Makdisi, George, The scholastic method in medieval education: An inquiry into its origins in law and theology, Speculum 49/4 (1974) 640-661.

Novikoff, Alex J., The Medieval Culture of Disputation: Pedagogy, Practice, and Performance (Philadelphia, 2013.)

Onoda, Shunzo, Monastic Debate in Tibet: A Study on the History and Structures of Bsdus Grwa Logic (Vienna, 1992).

Perdue, Daniel, Debate in Tibetan Buddhism (Ithaca, 1992).

Sa skya Paṇita, mKhas pa la 'jug pa'i sgo, in Sa paṇ Kun dga' rgyal mtshan gyi gsung 'bum, vol. 1 (Lhasa, 1992) 459-501 [in Tibetan].

Tillemans, Tom, Dharmakirti, in: Edward N. Zalta (ed.), The Stanford Encyclopedia of Philosophy (Stanford, 2017). Accessed on 3 October 2019: plato.stanford.edu/archives/spr2017/ entries/dharmakiirti/. 